\title{
BIOADHESIVE BUCCAL DISCS OF FLUVASTATIN SODIUM
}

\section{BY}

\author{
Nada Abdulla Assaedi ${ }^{1}$, Nagia N. Afifi ${ }^{2}$, Gehanne A. Awad ${ }^{1}$
}

\section{FROM}

${ }^{\mathbf{1}}$ Department of Pharmaceutics and Industrial Pharmacy, Faculty of Pharmacy, Ain Shams University, Cairo, Egypt; ${ }^{2}$ Department of Pharmaceutical Technology, Faculty of Pharmacy and Biotechnology, German University in Cairo, Cairo, Egypt

\begin{abstract}
Fluvastatin sodium (FVS) is a cholesterol lowering agent (HMG-CoA reductase inhibitor) which undergoes extensive hepatic first pass metabolism causing an absolute bioavailability of $\sim 30 \%$. The aim of this work was to formulate a buccoadhesive disc of FVS to be applied to the buccal mucosa, releasing the drug in a unidirectional manner, in order to improve the bioavailability of the drug and lower the dose-dependent side effects. The bioadhesive discs were prepared by direct compression method using several polymers such as: guar gum, sodium alginate, sodium carboxymethyl cellulose, carbopol 934P, and hydroxypropylmethyl cellulose. Impermeable ethyl cellulose was applied as the backing layer. Different permeation enhancers such as bile salts, surfactants, fatty acids, chitosan, dimethyl sulfoxide, and polyethylene glycol 6000 (PEG 6000) were tested to improve the permeability of buccal mucosal membranes. The optimized formulation contained FVS, guar gum, PEG 6000, and sodium deoxycholate (permeation enhancer, 4\%). It showed a drug release of $95.4 \%$ in $80 \mathrm{~min}$, drug permeation through chicken pouch membrane (flux $\left(\mathrm{J}_{\mathrm{ss}}\right)=3.74 \mathrm{mg} \mathrm{cm}^{-2} \mathrm{~h}^{-1}$ ), ex vivo bioadhesion strength of $2.543 \mathrm{~g}$, along with satisfactory bioadhesion time of $4.87 \mathrm{~h}$. Physicochemical characteristics of the buccal discs such as drug content uniformity, disc thickness, disc hardness, surface $\mathrm{pH}$, and swelling index were also evaluated.
\end{abstract}

Keywords: Fluvastatin sodium, bioadhesive buccal discs, PEG 6000, sodium deoxycholate. 


\section{Introduction}

Oral drug administration is the most suitable and widely acceptable route for the delivery of most therapeutically active agents. However, many drugs are subjected to presystemic clearance in the liver, which often leads to a lack of correlation between membrane permeability, absorption and bioavailability (Harris and Robinson, 1992). In recent years, delivery of therapeutic agents through various transmucosal routes has received significant attention. Among these, the buccal route provides a number of advantages such as well vascularization, relatively large surface area of absorption, ease of accessibility, simple delivery devices, feasibility of controlled drug delivery, avoidance of gastrointestinal degradation and hepatic first pass metabolism due to direct access of the drug into the systemic circulation through the internal jugular vein (Neelagiri et al., 2013).

The most important determinant of buccal delivery is the degree of permeability of the mucosa since the therapeutic efficacy of a drug mainly depends on its ability to penetrate the tissue fast enough to provide the required effective plasma concentrations (De Caro et al., 2009). Permeation enhancers may be utilized to overcome the permeability barrier in which they act by increasing the retention time of drug around the buccal mucosa, interaction with the buccal mucosal protein and intercellular lipid, and/or enhancing the drug partitioning across the buccal mucosa (Meher et al., 2012). In addition, drug absorption through the oral mucosal membranes requires that the drug dissolves sufficiently in a very small volume of saliva, which may represent an obstacle for poorly soluble drugs (Turunen et al., 2011).

Fluvastatin sodium (FVS) is an antilipemic agent which competitively inhibits hydroxymethylglutaryl-coenzyme A (HMG-CoA) reductase. FVS belongs to a class of medications called statins and is widely used to reduce plasma cholesterol levels and prevent cardiovascular disease. However, it undergoes extensive hepatic first pass metabolism causing an absolute bioavailability of $~ 30 \%$ (Sweetman, 2005). Thereby, a new approach to increase its bioavailability will be of prime benefit. With its low oral bioavailability, short half-life of 2-3 hours, and suitable molecular size of $433.45 \mathrm{~g} / \mathrm{mol}$, FVS is considered a good candidate for buccal route administration which has the benefit of escaping first pass effect as the drug passes directly into the bloodstream resulting in a reduction of dose and dose-dependent adverse events.

\section{Materials and methods}

\section{Materials}

FVS was kindly gifted by Biocon Ltd, Bangalore, India. Guar gum (GG), sodium alginate (SALG), sodium carboxymethyl cellulose, high viscosity (SCMC), hydroxypropylmethyl cellulose, 4,000 cp (HPMC), sodium cholate (SC), sodium deoxycholate (SDC), cetrimide, and dimethyl sulfoxide (DMSO) were purchased from Sigma Chemicals, USA. Chitosan was obtained from Acros Organics, USA. Carbopol 934P (CP) was obtained from Goodrich Chemical Co., USA. 2-pyrrolidone was obtained from Aldrich, USA. Polyethylene glycol 6000 (PEG), microcrystalline cellulose (MCC), ethyl cellulose (EC), sodium lauryl sulfate (SLS), tween 80, oleic acid, magnesium stearate $(\mathrm{MgSt})$, sodium chloride $(\mathrm{NaCl})$, potassium dihydrogen phosphate $\left(\mathrm{KH}_{2} \mathrm{PO}_{4}\right)$, and disodium hydrogen phosphate $\left(\mathrm{Na}_{2} \mathrm{HPO}_{4}\right)$ anhydrous were purchased from El-Nasr Pharmaceutical Chemical Co., Cairo, Egypt. 


\section{Preparation of bioadhesive buccal discs}

Disc compositions are shown in Tables (1-2). The ingredients were accurately weighed and mixed in a glass mortar and pestle for 10 minutes. Magnesium stearate was added as lubricant and mixed again for 2 minutes. The discs were prepared manually by direct compression method using a flat faced $12 \mathrm{~mm}$ punch. First, the powder mix was precompressed then the backing layer of ethyl cellulose was added and compressed at maximum force. The peripheral sides of the discs were coated with EC in ethanol solution $(10 \% \mathrm{w} / \mathrm{v})$ by brushing and were left to dry in room temperature. The design of the buccal disc is shown in Figure 1. The main function of the backing layer is to provide unidirectional drug flow to the buccal mucosa and prevent the drug from being dissolved in saliva and hence swallowed (Neelagiri et al., 2013). MCC and PEG 6000 were used as release enhancers.

\section{Release study}

The release rate from buccal discs was studied using USP type II (paddle) dissolution test apparatus (Hanson SR8 plus dissolution tester, Germany). Buccal discs were fixed to a glass slide sitting at the bottom of the dissolution flask using an instant adhesive (cyanoacrylate) so that the core layer was facing the dissolution medium. The space between the paddle and the buccal disc was $2.5 \mathrm{~cm}$. The dissolution medium comprised $500 \mathrm{~mL}$ phosphate buffer $\mathrm{pH} 6.8$ to simulate buccal environment and maintain sink conditions. The release study was performed at $37 \pm 0.5^{\circ} \mathrm{C}$ with a rotation speed of $50 \mathrm{rpm}$. Samples of $5 \mathrm{~mL}$ were withdrawn, replaced with fresh medium at time intervals: 15, 30, 60, 90, 120, 150, 180, 210, and $240 \mathrm{~min}$, and analyzed using UV spectrophotometer (Shimadzu UV visible 1601 PC, Kyoto, Japan) at $303 \mathrm{~nm}$. Experiments were performed in triplicate $(n=3)$.

In order to determine the drug release mechanism from the prepared discs, the release data (up to $60 \%$ release) of the optimized formulation was fitted to the Korsmeyer-Peppas equation (Peppas, 1985):

$\mathrm{M}_{\mathrm{t}} / \mathrm{M}_{\infty}=\mathrm{kt}^{\mathrm{n}}$, Eq. (1)

where $\mathrm{M}_{t} / \mathrm{M}_{\infty}$ is the fractional release of the drug, ' $\mathrm{t}$ ' denotes the release time, ' $k$ ' represents a constant, incorporating structural and geometrical characteristics of the drug/polymer system, and ' $n$ ' is the diffusional exponent and characterizes the type of release mechanism during the dissolution process. For the case of cylindrical discs, $\mathrm{n} \leq$ 0.45 corresponds to a Fickian (case I) diffusion, $0.45<\mathrm{n}<0.89$ to an anomalous (nonFickian) transport (where release is controlled by a combination of diffusion and polymer relaxation), $\mathrm{n}=0.89$ to a zero order (case II) transport (where the drug release rate is independent of time and involves polymer relaxation), and $n>0.89$ to a super case II transport (Harland et al., 1988).

\section{Permeation study}

Chicken pouch mucosa, an easily available biological membrane having a nonkeratinized uniform surface morphology similar to humans (Maswadeh et al., 2010), 
was chosen as a model membrane for this study. Chicken heads were obtained immediately post sacrifice from a local slaughterhouse and transported to the laboratory. The excised mucosa was immersed in isotonic saline at $60^{\circ} \mathrm{C}$ for $1 \mathrm{~min}$ and the epithelium was then peeled away from the connective tissue by heat separation method (Kulkarni et al., 2010). Resulting membranes of thickness $\sim 180-200 \mu \mathrm{m}$ were briefly dipped in distilled water and frozen until use in a period of 3 weeks.

Permeation study was performed using a modified USP type II (paddle) dissolution test apparatus (Hanson SR8 plus dissolution tester, Germany). Figure 2 displays the method where the buccal membrane was stretched over an open end of a glass tube $(13 \mathrm{~mm}$ diameter, opened from both ends) and made water tight by rubber band forming the donor chamber. The tube was then immersed in $500 \mathrm{~mL}$ phosphate buffer saline $\mathrm{pH} 7.4$ contained in the dissolution flask so that the membrane was just below the surface of the recipient solution (Mohamed et al., 2011). The temperature was maintained at $37 \pm 0.5^{\circ} \mathrm{C}$ and paddle speed was set at $100 \mathrm{rpm}$. The buccal membrane was allowed to stabilize for $1 \mathrm{~h}$ before applying the buccoadhesive disc inside the tube. Donor compartment was filled with $1 \mathrm{~mL}$ phosphate buffer $\mathrm{pH}$ 6.8. Samples of $5 \mathrm{~mL}$ were withdrawn and replaced with fresh medium at time intervals: 0.5, 1, 1.5, 2, 2.5, 3, 3.5, 4, 5 , and $6 \mathrm{~h}$.

The formula yielding the highest permeation was selected for further study with permeation enhancers. Ten permeation enhancers were used in different concentrations: bile salts (sodium cholate and sodium deoxycholate), surfactants (tween 80, sodium lauryl sulfate, and cetrimide), fatty acid (oleic acid), chitosan, 2-pyrrolidone, dimethyl sulfoxide, and polyethylene glycol 6000 (Dodla and Velmurugan, 2013). The experiments were performed 4 times $(n=4)$.

The cumulative amount of permeated drug (mg) was plotted versus time (h) and steady-state flux was measured from the slope of the linear portion of the plot using the following equation:

Flux $=J_{\mathrm{ss}}=(\mathrm{dQ} / \mathrm{dt}) / \mathrm{A}$, Eq. $(2)$

where $J_{\mathrm{ss}}$ is the steady-state flux; $\mathrm{dQ} / \mathrm{dt}$ is the permeation rate; $\mathrm{A}$ is the active diffusion area $\left(1.33 \mathrm{~cm}^{2}\right.$ ). The permeability coefficient $\mathrm{P}$ was calculated as follows (De Caro et al., 2008):

$\mathrm{P}=\mathrm{J}_{\mathrm{ss}} / \mathrm{C}_{\mathrm{d}}$, Eq. (3)

where $\mathrm{P}$ is the permeability coefficient and $\mathrm{C}_{\mathrm{d}}$ is the donor drug concentration.

\subsection{Bioadhesion study (ex vivo)}

\subsubsection{Bioadhesion strength}

Several techniques have been reported in literature for the measurement of bioadhesive strength. In the present study, bioadhesive strength was measured using the modified physical balance method. The method utilized chicken pouch membrane as the model 
mucosal membrane. A piece of mucosa was fixed to the lower stainless steel support with a cyanoacrylate adhesive and moistened with phosphate buffer $\mathrm{pH} 6.8$. The disc was attached to the upper clamp of the apparatus using cyanoacrylate. The lower support was slowly raised so that the disc touched the mucosa. Then both pans were balanced by adding an appropriate weight to the left-hand pan. Previously weighed empty beaker was placed on the right hand pan. A preload of $50 \mathrm{~g}$ was placed on the clamp for $1 \mathrm{~min}$ to establish the adhesive bond, then water (equivalent to weight) was slowly added to the beaker at a constant rate until the disc detached from the mucosal surface (Velmurugan and Srinivas, 2013; Sudarshan et al., 2014). The weight required to detach the disc from the mucosal surface gave the measure of bioadhesive strength. The experiment was performed on 6 discs of each formulation using a different chicken pouch membrane each time. From the bioadhesive strength $(\mathrm{g})$, force of adhesion was calculated.

Force of adhesion $(\mathrm{N})=($ Bioadhesive strength $(\mathrm{g}) / 1,000) \times 9.81$ Eq. (4)

\section{Bioadhesion time}

The ex vivo bioadhesion time was studied by the application of buccoadhesive discs on freshly obtained chicken buccal mucosa. Mucosal membrane was fixed on the internal side of a beaker using cyanoacrylate. Discs were pasted onto the membrane by applying a light force for $30 \mathrm{~s}$. The beaker was filled with $200 \mathrm{~mL}$ phosphate buffer $(\mathrm{pH}$ 6.8) and kept at $37 \pm 1^{\circ} \mathrm{C}$. After 2 minutes, a $50 \mathrm{rpm}$ stirring was applied to simulate the buccal cavity environment. Time for disc to detach or completely dissolve was recorded as the bioadhesion time (Sudarshan et al., 2014). The experiment was performed in triplicate.

\section{Evaluation of physicochemical characteristics}

Physicochemical characteristics of the optimized formula were evaluated including the swelling index, drug content uniformity, disc thickness, disc hardness, and surface $\mathrm{pH}$.

Swelling Index: Three buccal discs were individually weighed $\left(\mathrm{W}_{1}\right)$ and placed separately in petri dishes with $5 \mathrm{~mL}$ of phosphate buffer of $\mathrm{pH} 6.8$. At the time interval of $15,30,60,90$, and $120 \mathrm{~min}$, disc was removed from the petri dish and carefully blotted using filter paper (Bhanja et al., 2013). The swollen disc was then reweighed $\left(\mathrm{W}_{2}\right)$ and the percentage hydration was calculated using the following formula:

Percentage hydration $=\left[\left(\mathrm{W}_{2}-\mathrm{W}_{1}\right) / \mathrm{W}_{1}\right] * 100$

Drug content uniformity was evaluated by dissolving one buccal disc in $250 \mathrm{~mL}$ phosphate buffer ( $\mathrm{pH}$ 6.8). The solution was then passed through a whatmann filter paper and analyzed spectrophotometrically at the predetermined $\lambda \max$ of FVS after sufficient dilution with phosphate buffer of pH 6.8 (Kassem et al., 2014). The test was done in triplicate and the mean drug content was deduced \pm SD. 
Disc thickness of three buccoadhesive discs was measured using a micrometer (Tri-Circle, Shanghai, China) and recorded.

2.6.4. Disc hardness was measured using a hardness tester (Erweka, Germany) for six buccoadhesive discs.

Surface $\mathrm{pH}$ was found by placing one disc in a petri dish in contact with $1 \mathrm{~mL}$ of phosphate buffer $(\mathrm{pH}$ 6.8) for 2 hours at room temperature. The $\mathrm{pH}$ was identified by bringing the electrode into contact with the disc surface and allowing equilibration for 1 minute (Viswanadhan et al., 2012). The experiment was repeated three times.

\section{RESULTS AND DISCUSSION}

\section{Release study}

The maximum duration for buccal drug delivery is usually limited to approximately 4-6 h, since meal intake and/or drinking may require dosage form removal (Neelagiri et al., 2013). Therefore, a formulation with an appropriate release profile of at least $80 \%$ drug release over a $3 \mathrm{~h}$ period was desired for the purpose of this study. The obtained release curves of F1-F25 are shown in Figure 3.

Discs containing single polymers (F1-F4) showed a slow drug release of less than $50 \%$ in $4 \mathrm{~h}$. On the other hand, discs containing HPMC (F5) released $90 \%$ of the drug in $2 \mathrm{~h}$ but they were excluded due to rapid erosion. Therefore, a blend of HPMC and each of the other polymers was formed in a 1:1 ratio (F6-F9) as a way to improve the release and minimize erosion. CMC-HPMC and SALG-HPMC blends showed improved drug release over the use of CMC or SALG alone, whereas in the GG and CP formulas, the addition of HPMC did not improve drug release.

MCC and PEG 6000 were added in $15-35 \% \mathrm{w} / \mathrm{w}$ as release enhancers to previous formulas F1-F4 and F6-F9. PEG 6000 was reported to increase porosity of the matrix and produce channels, which in turn facilitate the dissolution medium to penetrate the matrix and dissolve the drug more rapidly (Hassan et al., 2009). MCC allows water to enter the disc matrix by means of capillary pores and exhibits very good disintegrant property (Bala et al., 2012). GG (in F10 and F18) was the most influenced polymer by the addition of MCC or PEG where it released $>90 \%$ in $3 \mathrm{~h}$ compared to only $11.3 \%$ using GG alone (F1). When release enhancers were added to HPMC polymer blends, these formulas showed the highest drug release rates. However, F14 and F22 were excluded due to excessive swelling which caused the discs to come off the glass slide. Therefore, the selected formulations which showed $\geq 80 \%$ drug release in $3 \mathrm{~h}$ were: F10, F11, F15, F16, F18, F23, and F24. They were tested for drug permeation through chicken pouch mucosa.

Drug release of formula F27 is shown in Figure 4. F27 was picked as the optimized formulation as will be discussed in section "3.2. Permeation Study". F26 and F28 were therefore not tested for drug release since all three formulations (F26-F28) were expected to have higher drug release than F18 (70 GG, 30 PEG) due to possessing higher PEG concentrations. The formulation F27 showed a drug release of $95.4 \%$ in 80 
min. The values of $\mathrm{T}_{50 \%}, \mathrm{~T}_{70 \%}$ and $\mathrm{T}_{90 \%}$ were found to be 13.8, 24.2, and $49 \mathrm{~min}$ respectively. Polymeric matrices release the drug via a combination of mechanisms. Korsmeyer-Peppas release exponent (n) was found to be 0.742 , indicating anomalous (non-Fickian) release kinetics, where different processes such as diffusion, swelling, and erosion simultaneously occurred. The obtained value of $\mathrm{k}$ (kinetic constant), $\mathrm{n}$ (diffusional exponent) and $\mathrm{R}^{2}$ (correlation coefficient) of the in vitro release data are presented in Table 3.

\section{Permeation study}

Initial permeation results of the selected 7 formulations were in the range of 2.9$6.6 \%$ drug permeation in $4 \mathrm{~h}$. The formula with the highest permeation, F18 (70 GG, 30 PEG), was chosen for further evaluation with permeation enhancers.

Upon using different permeation enhancers with formula F18 (Table 4), sodium deoxycholate (SDC) was found to be the most effective enhancer. Addition of SDC results in the extraction of mucosal lipids from the intercellular spaces, via micellization, which enhances the diffusivity of the drug through the paracellular route. At higher concentrations, SDC perturbs the lipid membranes of the epithelial cells, possibly facilitating transcelluar transport as well (Ganem-Quintanar et al., 1997; Shanker et al., 2009). It was suggested that SDC can also cause the uncoiling and extension of the protein helices, which leads to opening of the polar pathways for diffusion (Nicolazzo et al., 2005).

Although the drug permeation has improved but it was still considered slow (11.8\% in $4 \mathrm{~h}$ using $4 \%$ SDC). This was probably due to the inability to release the drug in the small volume of liquid available. Therefore, F18 formulation had been changed concerning the ratio of guar gum to PEG 6000. New formulations: F26, F27, and F28 were prepared with decreasing GG and increasing PEG concentrations (Chinta et al., 2014). PEG 6000 has also been used as a permeation enhancer for buccal delivery of Simvastatin (Goud and Samanthula, 2011) and Atorvastatin calcium (John et al., 2010). SDC (4\%) was added to the new formulas and permeation was tested again.

Results are shown in Table 5. Formulations F27 and F28 demonstrated acceptable drug permeation of $75.6 \%$ and $81.2 \%$ in $4 \mathrm{~h}$ respectively. Table 6 lists a comparison of permeation properties of the two formulations such as permeation flux (J) and permeability coefficient. Permeation curve of the chosen formula F27 is displayed in Figure 5.

\section{Bioadhesion study}

Formulas F27 and F28 were evaluated for their bioadhesion properties. F27 showed a higher bioadhesion strength $(2.534 \mathrm{~g})$ than F28 (1.668 g). Increase in polymer concentration (40mg GG in F27 compared to 30mg GG in F28) resulted in increased force of adhesion. When the concentration of polymer is low, the number of chains penetrating glycoprotein chains per unit volume of mucus is low resulting in weaker interaction (Salamat-Miller et al., 2005). 
In addition, F27 had a bioadhesion time of $(4.87 \mathrm{~h})$, while F28 was able to remain attached to the buccal mucosa for only $(3.48 \mathrm{~h})$. The residence time of the disc should be 4-6 h for maximal release and permeation of drug. Therefore, F27, with its acceptable permeation profile and better bioadhesion property, was chosen for the following in vivo bioavailability study.

\section{Evaluation of physicochemical characteristics}

The disc swelling behavior is presented in Table 7. It showed considerable swelling of the polymer matrix ( $71.5 \%$ in $2 \mathrm{~h}$ ) allowing the drug to diffuse out at a fast rate. Appropriate swelling behavior of a buccal adhesive dosage form is essential for uniform release of the drug and effective mucoadhesion (Patel et al., 2007).

The disc surface $\mathrm{pH}$ was found to be $6.31 \pm 0.017$ which is within the acceptable salivary $\mathrm{pH}$ range (5.5-7.0). Hence, it was assumed that the disc would produce no local irritation to the mucosal surface (Hassan et al., 2009).

Tables and Figures:

Table 1. Composition of bilayered buccoadhesive discs (in milligrams)

\begin{tabular}{|c|c|c|c|c|c|c|c|}
\hline $\mathbf{F}$ & $\overline{G G}$ & SCMC & $\overline{\text { SALG }}$ & $\mathbf{C P}$ & HPMC & $\mathrm{MCC}$ & PEG \\
\hline 1 & 100 & & & & & & \\
\hline 2 & & 100 & & & & & \\
\hline 3 & & & 100 & & & & \\
\hline 4 & & & & 100 & & & \\
\hline 5 & & & & & 100 & & \\
\hline 6 & 50 & & & & 50 & & \\
\hline 7 & & 50 & & & 50 & & \\
\hline 8 & & & 50 & & 50 & & \\
\hline 9 & & & & 50 & 50 & & \\
\hline 10 & 70 & & & & & 30 & \\
\hline 11 & & 70 & & & & 30 & \\
\hline 12 & & & 70 & & & 30 & \\
\hline 13 & & & & 70 & & 30 & \\
\hline 14 & 40 & & & & 40 & 20 & \\
\hline 15 & & 40 & & & 40 & 20 & \\
\hline 16 & & & 30 & & 30 & 40 & \\
\hline 17 & & & & 30 & 30 & 40 & \\
\hline 18 & 70 & & & & & & 30 \\
\hline 19 & & 70 & & & & & 30 \\
\hline 20 & & & 70 & & & & 30 \\
\hline 21 & & & & 70 & & & 30 \\
\hline 22 & 40 & & & & 40 & & 20 \\
\hline 23 & & 40 & & & 40 & & 20 \\
\hline 24 & & & 30 & & 30 & & 40 \\
\hline 25 & & & & 30 & 30 & & 40 \\
\hline
\end{tabular}

Note: All formulations contain $21.06 \mathrm{mg}$ FVS (equivalent to $20 \mathrm{mg}$ fluvastatin) +1.2 mg MgSt 
Backing layer: $80 \mathrm{mg}$ EC

Abbreviations: GG, guar gum; SCMC, sodium carboxymethyl cellulose; SALG, sodium alginate; CP, carbopol 934P; HPMC, hydroxypropylmethyl cellulose; MCC, microcrystalline cellulose; PEG, polyethylene glycol 6000; FVS, fluvastatin sodium; $\mathrm{MgSt}$, magnesium stearate; EC, ethyl cellulose.

Table 2. Composition of bilayered buccoadhesive discs (in milligrams)

\begin{tabular}{|l|l|l|}
\hline F & GG & PEG \\
\hline $\mathbf{2 6}$ & 60 & 40 \\
\hline $\mathbf{2 7}$ & 40 & 60 \\
\hline $\mathbf{2 8}$ & 30 & 70 \\
\hline
\end{tabular}

Note: All formulations contain $21.06 \mathrm{mg}$ FVS (equivalent to $20 \mathrm{mg}$ fluvastatin) +1.2 $\mathrm{mg} \mathrm{MgSt}$

Backing layer: $80 \mathrm{mg} \mathrm{EC}$

Abbreviations: GG, guar gum; PEG, polyethylene glycol 6000; FVS, fluvastatin sodium; MgSt, magnesium stearate; EC, ethyl cellulose.

Table 3. Release analysis for F27 buccoadhesive disc

\begin{tabular}{|l|l|l|l|}
\hline Release model & $\begin{array}{l}\text { Release exponent } \\
(\mathrm{n})\end{array}$ & Kinetic constant $(\mathrm{k})$ & $\begin{array}{l}\text { Coefficient of } \\
\text { determination }\left(\mathrm{R}^{2}\right)\end{array}$ \\
\hline $\begin{array}{l}\text { Korsmeyer- } \\
\text { Peppas }\end{array}$ & 0.742 & $0.071 \% \mathrm{~min}^{-\mathrm{n}}$ & 0.998 \\
\hline
\end{tabular}


Table 4. Permeation of F18 using permeation enhancers

\begin{tabular}{|c|c|c|c|}
\hline \multicolumn{2}{|c|}{ Permeation enhancer } & $\begin{array}{l}\text { Amount } \\
\text { permeated } \\
\text { in } 4 \mathrm{~h} \\
(\mathrm{mg})\end{array}$ & $\begin{array}{c}\text { Drug } \\
\text { percent } \\
\text { permeated } \\
\text { in } 4 \mathrm{~h}\end{array}$ \\
\hline \multicolumn{2}{|l|}{ No enhancer } & 1.32 & $6.6 \%$ \\
\hline \multirow{2}{*}{ Sodium cholate } & $2 \%$ & 1.33 & $6.7 \%$ \\
\hline & $4 \%$ & 2.12 & $10.5 \%$ \\
\hline \multirow{2}{*}{ Sodium deoxycholate } & $2 \%$ & 1.66 & $8.3 \%$ \\
\hline & $\underline{4 \%}$ & $\underline{2.35}$ & $\underline{11.8 \%}$ \\
\hline \multirow{2}{*}{ Tween 80} & $4 \%$ & 1.42 & $7.1 \%$ \\
\hline & $8 \%$ & 1.50 & $7.5 \%$ \\
\hline \multirow{2}{*}{ Sodium lauryl sulfate } & $1 \%$ & 1.61 & $8.1 \%$ \\
\hline & $2 \%$ & 2.04 & $10.2 \%$ \\
\hline \multirow{2}{*}{ Cetrimide } & $2 \%$ & 1.33 & $6.7 \%$ \\
\hline & $4 \%$ & 1.32 & $6.6 \%$ \\
\hline \multirow{2}{*}{ Chitosan } & $4 \%$ & 1.56 & $7.8 \%$ \\
\hline & $8 \%$ & 1.62 & $8.1 \%$ \\
\hline Oleic acid & $4 \%$ & 1.18 & $5.9 \%$ \\
\hline 2-Pyrrolidone & $4 \%$ & 1.30 & $6.5 \%$ \\
\hline Dimethyl sulfoxide & $4 \%$ & 1.27 & $6.4 \%$ \\
\hline
\end{tabular}

Table 5. Permeation of modified formulas in addition to $4 \%$ sodium deoxycholate

\begin{tabular}{|l|l|l|ll|lr|}
\hline \hline & GG $(\mathrm{mg})$ & PEG 6000 $(\mathrm{mg})$ & Amount & permeated & Drug & percent \\
\hline \hline F18 & 70 & 30 & 2.35 & $11.8 \%$ & \\
\hline F26 & 60 & 40 & 3.88 & $19.4 \%$ & \\
\hline F27 & 40 & 60 & 15.12 & $75.6 \%$ \\
\hline F28 & 30 & 70 & 16.24 & $81.2 \%$ & \\
\hline
\end{tabular}

Abbreviations: GG, guar gum; PEG 6000, polyethylene glycol 6000 
Table 6. Permeation and bioadhesion parameters of fluvastatin sodium discs

\begin{tabular}{||c|c|c|c|}
\hline & Parameters & F27 & F28 \\
\hline \hline \multirow{4}{*}{$\begin{array}{c}\text { Permeation } \\
\text { study }\end{array}$} & Amount of drug permeated in 4 h & $15.12 \pm 0.862$ & $16.24 \pm 0.784$ \\
\cline { 2 - 4 }$(\mathrm{mo})$ & Flux $(\mathrm{J})\left(\mathrm{mg} \mathrm{h}^{-1} \mathrm{~cm}^{-2}\right)$ & 3.743 & 4.068 \\
\cline { 2 - 4 } & Permeability coefficient $\left(\mathrm{cm} \mathrm{h}^{-1}\right)$ & 0.187 & 0.203 \\
\hline \multirow{3}{*}{$\begin{array}{c}\text { Bioadhesion } \\
\text { study }\end{array}$} & Bioadhesion strength (g) & $2.534 \pm 0.784$ & $1.668 \pm 0.697$ \\
\cline { 2 - 4 } & Bioadhesion force (N) & $0.025 \pm 0.008$ & $0.016 \pm 0.007$ \\
\cline { 2 - 4 } & Bioadhesion time (h) & $4.87 \pm 0.51$ & $3.48 \pm 0.39$ \\
\hline
\end{tabular}

Table 7. Swelling behavior of F27 buccoadhesive discs

\begin{tabular}{|c|c|}
\hline Time (min) & Percentage hydration (\%) \\
\hline 15 & 38.3 \\
\hline 30 & 46.9 \\
\hline 60 & 57.2 \\
\hline 90 & 65.4 \\
\hline 120 & 71.5 \\
\hline
\end{tabular}

Table 8. Physicochemical characteristics of F27 buccoadhesive disc

\begin{tabular}{|lc|}
\hline Drug content (\%) & $98.6 \pm 1.46$ \\
\hline Thickness (mm) & $1.94 \pm 0.042$ \\
\hline Hardness (N) & $58.67 \pm 5.033$ \\
\hline Surface pH & $6.31 \pm 0.017$ \\
\hline
\end{tabular}




\section{Bioadhesive + drug}

\section{Unidirectional \\ flow}

Figure 1. Bioadhesive buccal discs design

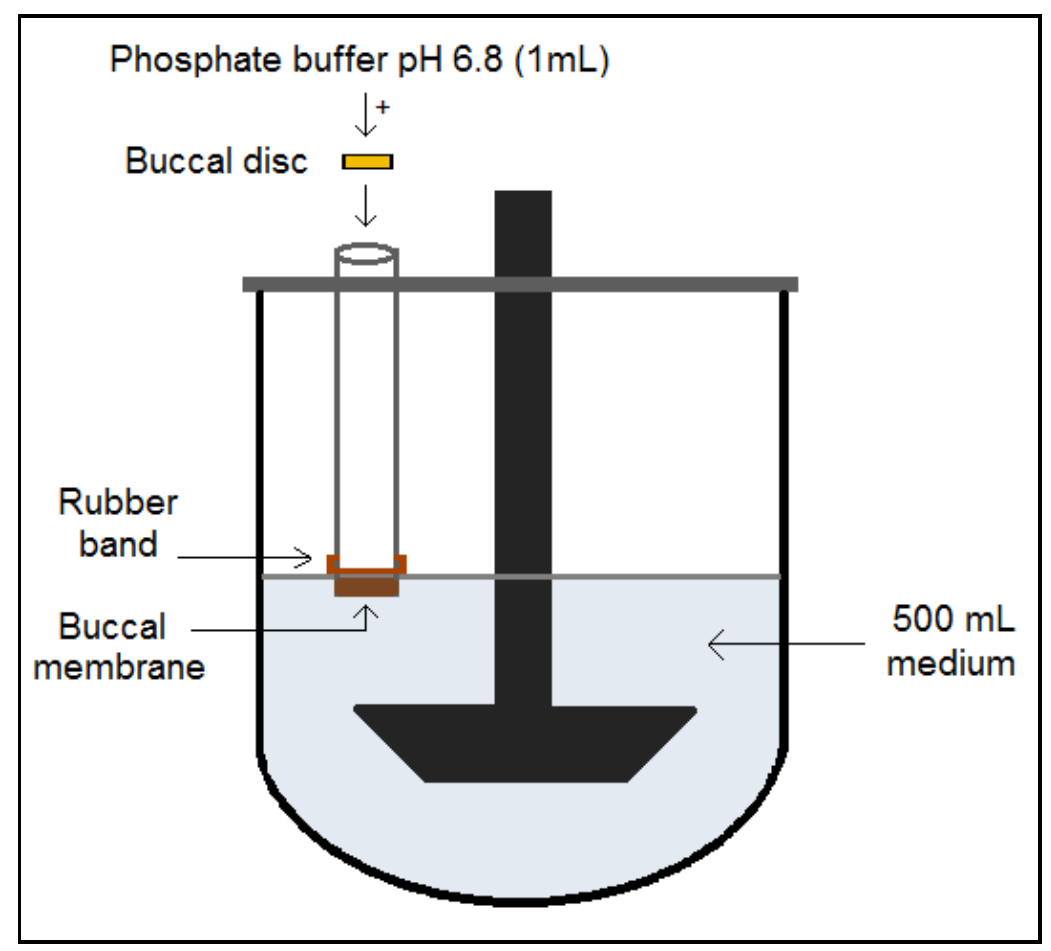

Figure 2. Permeation apparatus 


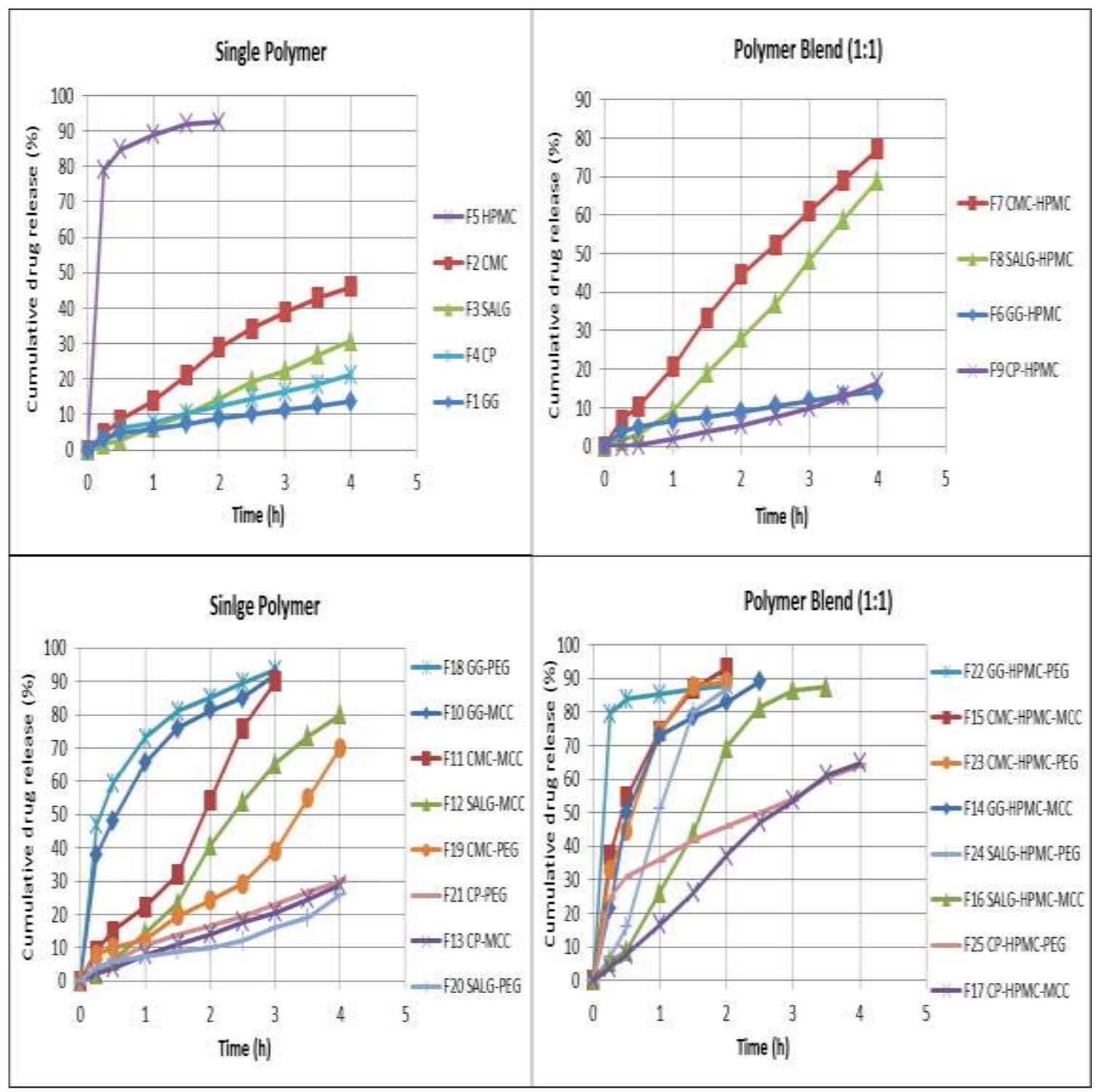

Figure 3. Release curves of F1-F25 bioadhesive buccal discs 


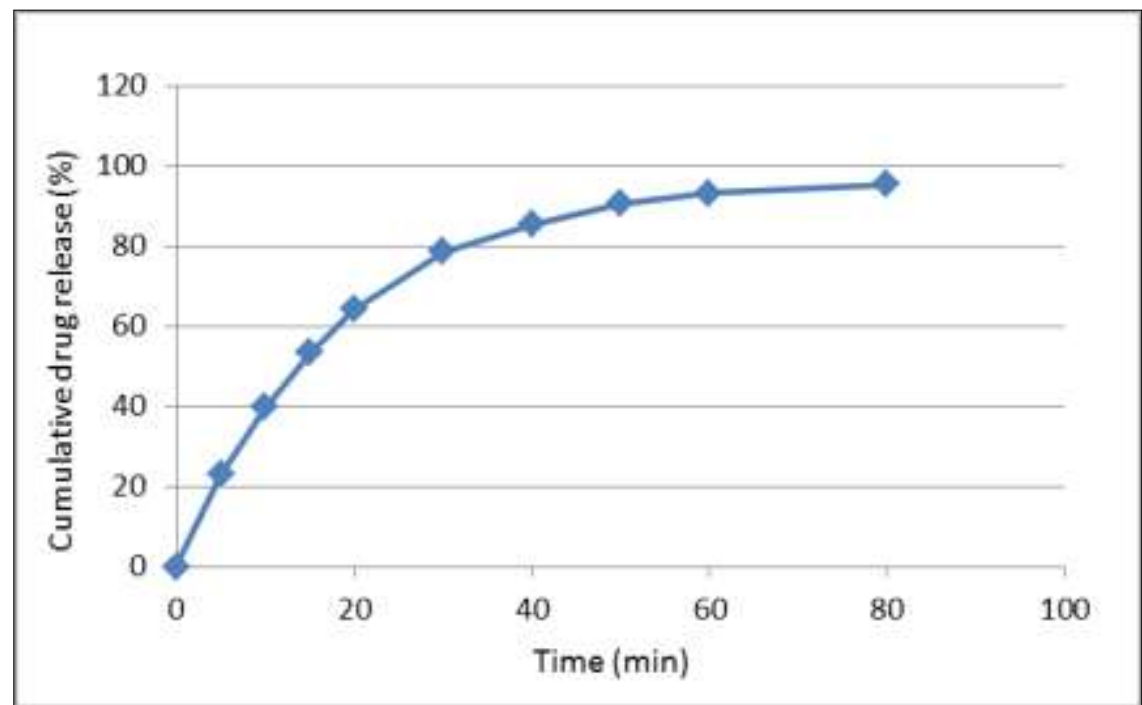

Figure 4. Release curve of formula F27

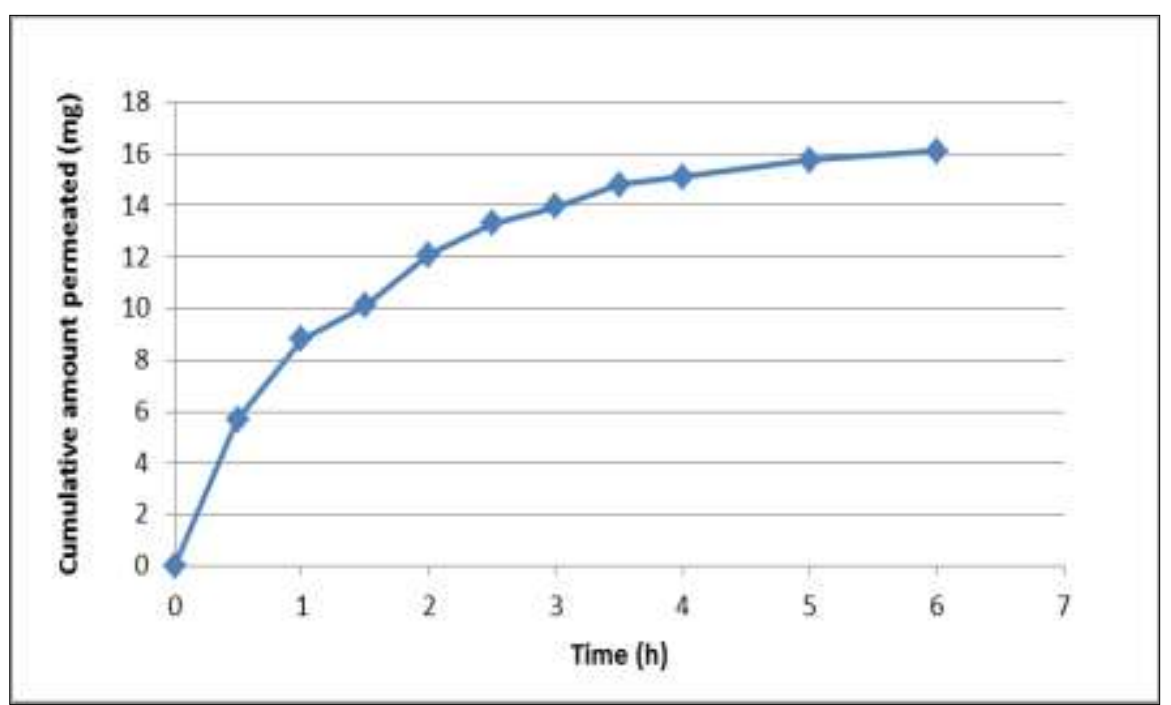

Figure 5. Permeation curve of optimized formula F27

\section{Conclusion}

The results of the study indicated that buccoadhesive discs of fluvastatin sodium could be successfully prepared by direct compression method using guar gum as the mucoadhesive polymer, PEG 6000 as the release enhancer, sodium deoxycholate as the permeation enhancer, and ethyl cellulose as the backing layer. It exhibited well drug release, bioadhesion property, and drug permeation in $4 \mathrm{~h}$. The mechanism of drug release was found to be non-Fickian diffusion. Therefore, there is a good potential of the prepared buccoadhesive discs for systemic delivery with added advantages of circumventing the hepatic first pass metabolism and substantial dose reduction. Further 
in vivo study is required to attain the relative bioavailability of this optimized buccal disc formulation in comparison to a peroral product in the market.

\section{Acknowledgment}

The authors are thankful to Biocon Ltd, Bangalore, India, for providing a generous gift sample of fluvastatin sodium.

\section{REFERENCES}

Bala, R., Khanna, S., Pawar, P., (2012):. Polymers in fast disintegrating tablets - A review. Asian J. Pharm. Clin. Res. 5, 8-14.

Barilla, D., Pratapa, P., Hubert, M., Gumbhir-Shah, K., (2004):. Steady-state pharmacokinetics of fluvastatin in healthy subjects following a new extended release fluvastatin tablet, Lescol ${ }^{\circledR}$ XL. Biopharm. Drug Dispos. 25, 51-59. DOI: 10.1002/bdd.378.

Bhanja, S., Shafeeque, C., Sudhakar, M., (2013):. Mucoadhesive buccal tablets of glimeperide - formulation and evaluation. Int. J. Pharm. Pharm. Sci. 5, 502510.

Chinta, B., Tnvss, S., Santosh, T., Nannapaneni, M., (2014):. Formulation and evaluation of diclofenac diethylamine gels prepared using hyaluronic acid: Influence of various permeation enhancers on rat skin penetration. Indo Amer. J. Pharm. Res. 4, 320-328.

De Caro, V., Giandalia, G., Siragusa, M.G., Paderni, C., Campisi, G., Giannola, L.I., (2008). Evaluation of galantamine transbuccal absorption by reconstituted human oral epithelium and porcine tissue as buccal mucosa models: Part I. Eur. J. Pharm. Biopharm. 70, 869-873.

De Caro, V., Giandalia, G., Siragusa, M.G., Campisi, G., Giannola, L.I., (2009). Galantamine delivery on buccal mucosa: Permeation enhancement and design of matrix tablets. J. Bioequiv. Availab. 1, 127-134.

Dodla, S., Velmurugan, S., (2013):. Buccal penetration enhancers - An overview. Asian J. Pharm. Clin. Res. 6, 39-47.

Ganem-Quintanar, A., Kalia, Y.N., Falson-Rieg, F., Buri, P., (1997):. Mechanisms of oral permeation enhancement. Int. J. Pharm. 156, 127-142.

Goud, B.A., Samanthula, K.S., (2011):. Formulation and evaluation of bioadhesive buccal tablets of simvastatin. J. App. Pharm. Sci. 1, 68-91.

Harland, R.S., Gazzaniga, A., Sangalli, M.E., Colombo, P., Peppas, N.A., (1988):. Drug/polymer matrix swelling and dissolution. Pharm. Res. 5, 488-494. 
Harris, D., Robinson, J.R., (1992):. Drug delivery via the mucous membranes of the oral cavity. J. Pharm. Sci. 81, 1-10.

Hassan, N., Khar, R.K., Ali, M., Ali, J., (2009):. Development and evaluation of buccal bioadhesive tablet of an anti-emetic agent ondansetron. AAPS Pharm. Sci. Tech. 10, 1085-1092. DOI: 10.1208/s12249-009-9304-4.

John, A.S., Sathesh, B.P.R., Divakar, G., Jangid, M.K., Purohit, K.K., (2010):. Development and evaluation of buccoadhesive drug delivery system for atorvastatin calcium. J. Curr. Pharm. Res. 1, 31-38.

Kassem, M.A., Elmeshad, A.N., Fares, A.R., (2014):. Enhanced bioavailability of buspirone hydrochloride via cup and core buccal tablets: formulation and in vitro/in vivo evaluation. Int. J. Pharm. 463, 68-90. DOI: 10.1016/j.ijpharm.2014.01.003.

Kulkarni, U., Mahalingam, R., Pather, I., Li, X., Jasti, B., (2010):. Porcine buccal mucosa as in vitro model: Effect of biological and experimental variables. J. Pharm. Sci. 99, 1265-1277. DOI: 10.1002/jps.21907.

Maswadeh, H.M., Kanaan, R.A., Aljarbou, A.N., Al-Hanbali, O.A, (2010):. Effect of different biological membranes on in vitro bioadhesion property. Drug Invent. Today 2, 155-159.

Meher, J.G., Yadav, N.P., Yadav, K.S., Rai, V., (2012):. Buccal drug delivery system and penetration enhancer: A review. The Pharm. Rev. 8, 113-117.

Mohamed, M., Haider, M., Ali, M., (2011):. Buccal mucoadhesive films containing antihypertensive drug: In vitro/in vivo evaluation. J. Chem. Pharm. Res. 3, 665-686.

Neelagiri, R., Reddy, M.S., Rao, N.G.R., (2013):. Buccal patch as drug delivery system: An overview. Int. J. Curr. Pharm. Res. 5, 40-47.

Nicolazzo, J., Reed, B., Finnin, B., (2005):. Buccal penetration enhancers - How do they really work? J. Control. Release 105, 1-15. DOI:10.1016/j.jconrel.2005.01.024.

Patel, V.M., Prajapati, B.G., Patel, M.M., (2007):. Formulation, evaluation, and comparison of bilayered and multilayered mucoadhesive buccal devices of propranolol hydrochloride. AAPS Pharm. Sci. Tech. 8, E147-E154.

Peppas, N.A., (1985):. Analysis of fickian and non-fickian drug release from polymers. Pharm. Acta Helv. 60, 110-111.

Salamat-Miller, N., Chittchang, M., Johnston, T.P., (2005):. The use of mucoadhesive polymers in buccal drug delivery. Adv. Drug Deliv. Rev. 57, 1666-1691. 
Shanker, G., Kumar, C.K., Gonugunta, C.S.R., Kumar, B.V., Veerareddy, P.R., (2009):. Formulation and evaluation of bioadhesive buccal drug delivery of tizanidine hydrochloride tablets. AAPS Pharm. Sci. Tech. 10, 530-539. DOI: 10.1208/s 12249-009-9241-2.

Sudarshan, S., Savaliya, D., Shah, S.D., Bothara, S.B., (2014):. Development and in vivo bioavailability evaluation of sumatriptan succinate buccal tabets. Int. J. Pharm. Sci. Nanotech. 7, 2477-2486.

Sweetman, S.C., editor, (2005):. Martindale: The Complete Drug Reference. 34th ed. London: The Pharmaceutical Press.

Turunen, E., Mannila, J., Laitinen, R., Riikonen, J., Lehto, V.P., Jarvinen, T., Ketolainen, J., Jarvinen, K., Jarho, P., (2011):. Fast-dissolving sublingual solid dispersion and cyclodextrin complex increase the absorption of perphenazine in rabbits. J. Pharm. Pharmacol. 63, 19-25. DOI: 10.1111/j.20427158.2010.01173.x.

Velmurugan, S., Srinivas, P., (2013):. Formulation and in vitro evaluation of losartan potassium mucoadhesive buccal tables. Asian J. Pharm. Clin. Res. 6, 125-130.

Viswanadhan, P.V., Padole, A., Abraham, A., Mathew, S.T., (2012):. Buccal tablets of lisinopril by direct compression method for buccal drug delivery. Int. R. J. Pharmaceuticals 2, 30-38. 


\section{الملخص العربي \\ أسطوانات فمية لاصقة لعقار صوديوم القلوفاستاتين}

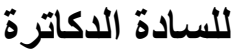

ندى عبداله الصاعدي'، ناجية نجيب عفيفي'، جيهان عبدالسميع عوض'

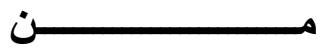

'قسم الصيدلانيات و الصيدلة الصناعية، كلية الصيدلة، جامعة عين شمس، ميدان العباسية، القاهرة، مصر

كَّم تكنولوجيا الصيدلة، كلية الصيدلة، الجامعة الألمانية في القاهرة، التجمع الخامس، القاهرة، مصر

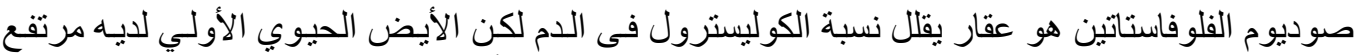

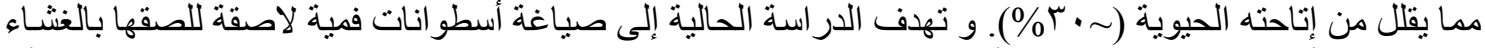

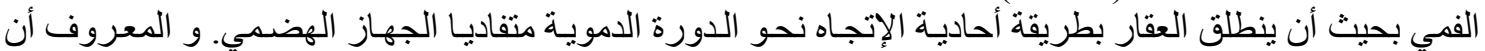



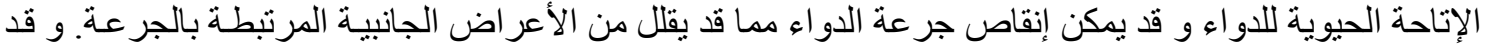

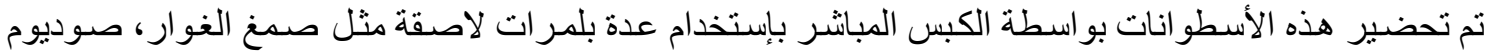

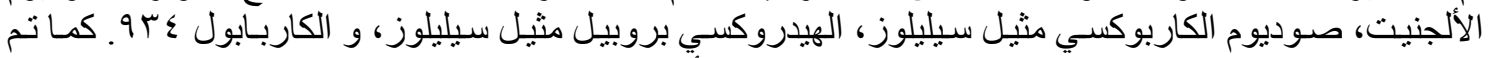

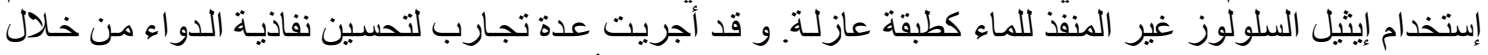

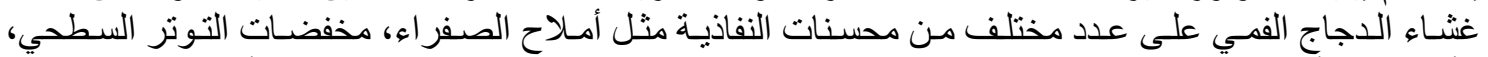

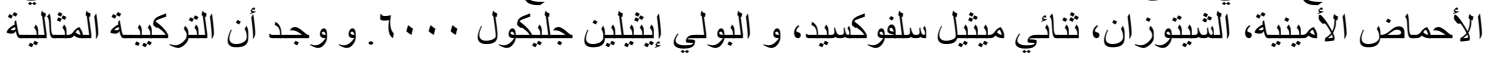

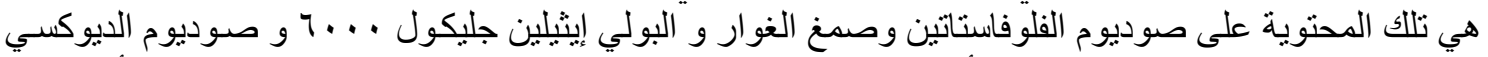



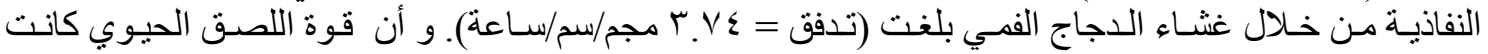



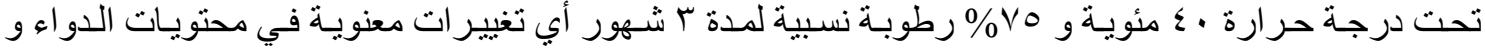



الكلمـات المفتاحيـة: صـوديوم الفلوفاستاتين، أسطو انات فميـة لاصـقة، البولي إيثيلين جليكول ... . 7، صـوديوم

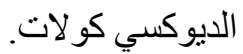

